(c) American Dairy Science Association, 2004.

\title{
Duration of Infection and Strain Variation in Streptococcus uberis Isolated from Cows' Milk
}

\author{
S. McDougall, ${ }^{1}$ T. J. Parkinson, ${ }^{2}$ M. Leyland, ${ }^{2}$ F. M. Anniss, ${ }^{1}$ and S. G. Fenwick ${ }^{3}$ \\ ${ }^{1}$ Animal Health Centre, Morrinsville, New Zealand \\ ${ }^{2}$ Institute of Veterinary, Animal and Biomedical Sciences, \\ Massey University, Palmerston North, New Zealand \\ ${ }^{3}$ School of Veterinary Clinical Science, Division of Health Sciences, \\ Murdoch University, Perth, Western Australia, 6150, Australia
}

\begin{abstract}
The duration of infection and pulsed-field gel electrophoresis (PFGE) types of bovine intramammary Streptococcus uberis isolates were examined. Milk samples were collected in duplicate from all 4 glands of 503 cows from 5 herds within 1 to $3 \mathrm{~d}$ of parturition and from 113 cows with clinical mastitis in the same herds throughout lactation. Glands from which $S$. $u b$ eris was isolated were resampled at 28-d intervals.

The prevalence of S. uberis was $12 \%$ for cows around parturition, and the median duration of infection was $16 \mathrm{~d}$. Cows $>2 \mathrm{yr}$ old had a longer duration of infection than 2 yr old cows, and duration varied among herds. A total of 173 different PFGE types were identified from a total of $234 \mathrm{~S}$. uberis isolates. Each farm had a unique set of PFGE types. Only 3 PFGE types were common to each of 3 pairs of cows, and these occurred on the same farm. Where S. uberis was isolated on more than one occasion from a gland, only $55 \%$ of the PFGE types were the same across time. For cows with multiple glands infected, only one-half (9 of 18) had the same PFGE type in more than one gland. No predominant PFGE type was identified in any herd.

It is concluded that there was wide heterogeneity of PFGE types, that the environment rather than other cows was the likely source of $S$. uberis infections, and that glands may be infected with multiple $S$. uberis PFGE types over a lactation.
\end{abstract}

(Key words: Streptococcus uberis, pulsed-field gel electrophoresis, mastitis, bovine)

Abbreviation key: PFGE = pulsed-field gel electrophoresis.

\section{INTRODUCTION}

Streptococcus uberis is the most common isolate from cases of clinical mastitis and is commonly found

Received November 2, 2003.

Accepted February 12, 2004.

Corresponding author: S. McDougall; e-mail: smcdoug@ahc.co.nz. in subclinical infections in early lactation (McDougall, 1998) and at the end of lactation (Williamson et al., 1995; Pankey et al., 1996) in New Zealand dairy cows. The prevalence of infection is related to the rate of new infection (the incidence rate) and the duration of infection (Bramley and Dodd, 1984). The duration of subclinical $S$. uberis infection has not been determined in the pasture-fed, seasonally calving New Zealand dairy industry. The duration of $S$. uberis infection has been reported as between $20 \mathrm{~d}$ and 9 mo in northern hemisphere studies (Todhunter et al., 1995; Watt, 1999; Zadoks, 2002).

Streptococcus uberis can be isolated from a number of sites on the cow including the vagina, tonsils, and escutcheon (Cullen, 1966) as well as from bedding and pasture (Bramley and Dodd, 1984; Todhunter et al., 1995). The main route of transmission appears to be from environmental sources. However, recent epidemiological and molecular typing studies have demonstrated that cow-to-cow transmission is likely to be occurring in some herds (Phuektes et al., 2001; Zadoks et al., 2001).

Variations in S. uberis strain type have been reported using restriction fragment length polymorphism (Hill and Leigh, 1989; Jayarao et al., 1992), randomly amplified polymorphic DNA (Gillespie et al., 1997; Gillespie et al., 1998; Zadoks, 2002), repetitive extragenic palindromic-polymerase chain reaction (Wieliczko et al., 2002), and pulsed-field gel electrophoresis (PFGE) procedures (Baseggio et al., 1997; Douglas et al., 2000; Phuektes et al., 2001). A large number of $S$. uberis types have been observed with all methods (Hill and Leigh, 1989; Jayarao et al., 1992; Douglas et al., 2000; Phuektes et al., 2001; Wieliczko et al., 2002; Zadoks et al., 2003). All S. uberis isolates from clinical cases of mastitis were in 2 of the 8 clusters defined from a group of subclinical and clinical $S$. uberis isolates when strains were analyzed with RFLP (Jayarao et al., 1992). Additionally, all S. uberis isolates from clinical cases had DNA fragments of $>21$ $\mathrm{kb}$; only $21 \%$ of subclinical isolates had such large 
Table 1. Descriptive data for enrolled herds.

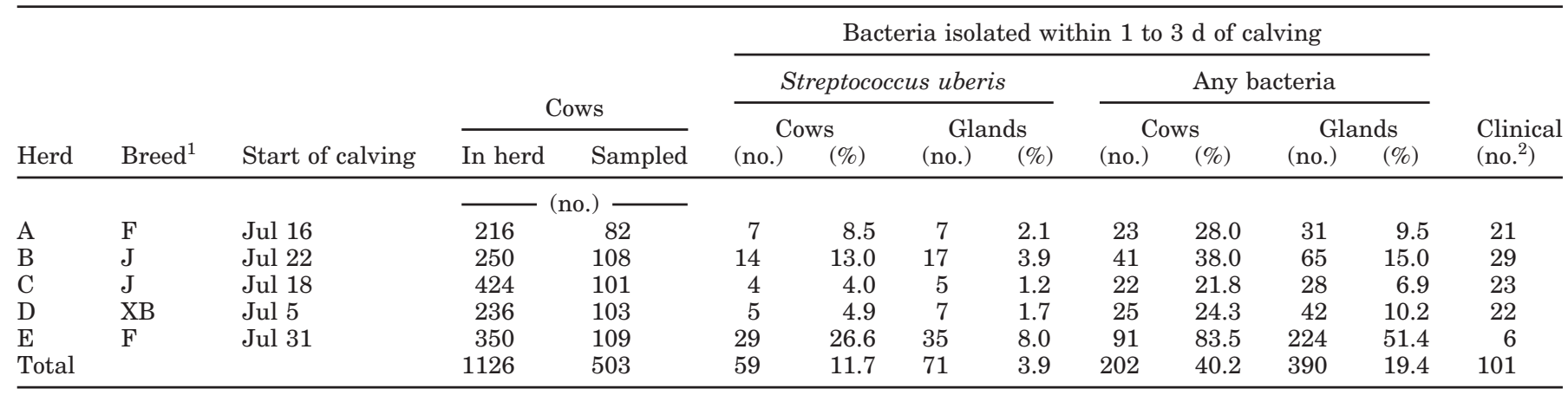

${ }^{1} \mathrm{~F}=$ Friesian, $\mathrm{J}=$ Jersey, and $\mathrm{XB}=$ Jersey-Friesian cross.

${ }^{2}$ Number of cows diagnosed by the herd owners with clinical mastitis in the entire lactation.

DNA fragments (Jayarao et al., 1992). Although multiple genotypes are invariably present, a predominant type has been found in some herds (Phuektes et al., 2001; Zadoks, 2002). The degree of homogeneity of $S$. uberis types isolated from a herd has been used to infer the predominant route of transmission. Where there is a predominant type present, it has been suggested that cow-to-cow transmission is likely; if a large number of types are present and no type predominates, then an environmental source of the pathogen is likely (Zadoks, 2002).

Variations in the pathogenicity of phenotypically different isolates of $S$. uberis have been reported following intramammary challenge (Hill, 1988). Additionally, one PFGE type was shown to be more likely associated with clinical mastitis than other types present in the same herd (Phuektes et al., 2001). Hence, genotypic differences, identifiable by molecular typing techniques, may be associated with differences in pathogenicity.

This study aimed to describe the duration of $S$. $u b$ eris infection under New Zealand dairy production systems and to re-assess duration with knowledge of the PFGE type.

\section{MATERIALS AND METHODS}

\section{Sampling Protocol}

Five herds were selected on the basis that they maintained a separate sub-herd containing those cows calved $<8$ milkings, maintained good records of all disease events, and where the herd managers were willing to collect milk samples from all cows with clinical mastitis. Four herds were in the Waikato region (Herds A to D), and the fifth herd was in the Manawatu region (Herd E) of New Zealand. All herds had a seasonal calving pattern that commenced in spring (July; Table 1), and the cows were fed predominantly on rye grass (Lolium perene) and white clover (Trifolium repens) pasture.

Each herd was visited 3 times weekly, and duplicate milk samples were collected from any cow that had calved in the previous 1 to $3 \mathrm{~d}$ (i.e., since the previous visit). These visits continued until approximately 100 cows from each herd had been sampled. Each teat end was scrubbed with a cotton wool ball dampened with $70 \%$ methanol, the first 3 strips of milk were discarded, and a 10-mL sample was collected from each gland into a factory-clean test tube. The teats were then recleaned and sampled a second time. Samples were transported at room temperature before being processed for bacteriology within $3 \mathrm{~h}$ of collection. An additional sample from each gland was collected at the same time for determination of SCC using a fluorometric cell counting technique (Fossomatic, Foss Electric, Hillerød, Denmark; operated by Livestock Improvement Corporation, Hamilton, New Zealand).

Any gland from which $S$. uberis was isolated (excluding contaminated samples and those with $<3$ colony forming units $/ 10 \mu \mathrm{L}$ ) was enrolled in the trial. Single milk samples were then collected from each enrolled gland at approximately 28 -d intervals. Sampling ceased from a cow when $S$. uberis was not isolated from 2 sequential samples from any enrolled gland or when lactation ended. Cows detected with clinical mastitis by the herd owner using the criteria of swelling and/or heat of a gland or visible change in the milk (e.g., clots, strings, etc.) had a single milk sample collected from all glands at the time of diagnosis and $21 \mathrm{~d}$ later. These samples were labeled and frozen at $-20^{\circ} \mathrm{C}$ until collection at the next routine farm visit. The glands with clinical signs were treated 3 times at 12-h intervals by intramammary infusions of $1 \mathrm{~g}$ of penicillin (Penalone, Schering-Plough, Upper Hutt, New Zealand), and the milk was discarded for $144 \mathrm{~h}$ following the last treatment. 


\section{Case Definitions}

A gland was defined as being infected with $S$. uberis where $\geq 3$ more colony forming units $/ 10 \mu \mathrm{L}$ were isolated from both samples (at initial enrolment) or a single sample (at resampling and from clinical cases) and where only one other colony type was present (which occurred on 15 occasions where coagulase-negative staphylococci, Staphylococcus aureus, or a yeast was co-isolated with $S$. uberis).

Bacteriological cure was defined as having occurred when 2 sequential samples were found not to contain S. uberis.

The duration of infection (days) was defined in 4 ways:

- as the interval from initial sampling to half way between the last $S$. uberis-positive sample and the first non- $S$. uberis positive sample for each gland, irrespective of PFGE type, where the gland was subsequently diagnosed with clinical mastitis and the duration was defined as the interval between initial sample and the day of clinical diagnosis;

- as in the first example, except that the duration included the period after diagnosis of clinical mastitis where clinical mastitis occurred;

- as in the first example except where the $S$. uberis PFGE type changed, in which case the duration was between initial isolation and half way between the final sampling from which the initial PFGE type was isolated and the first sample at which the new PFGE type was isolated; and

- as in the second example except the S. uberis PFGE type changed, in which case the duration was between initial isolation and half way between the final sampling from which the initial PFGE type was isolated and the first sample at which the new PFGE type was isolated

Where a gland was still infected at the end of lactation, the duration was defined as the interval from the initial sampling to the last $S$. uberis-positive sample that was collected at the routine sampling visit. Clinical failure was defined as having occurred where the herd owner chose to retreat a gland previously treated for clinical mastitis within $21 \mathrm{~d}$ of initial treatment.

\section{Microbiology}

Milk samples $(10 \mu \mathrm{L})$ were streaked onto one quarter of a $5 \%$ blood agar plate containing $0.1 \%$ esculin (Fort Richard, Auckland, New Zealand) and incubated at $37^{\circ} \mathrm{C}$ for $48 \mathrm{~h}$. The bacteria were provisionally speciated based on colony morphology, hemolysis pattern, esculin reaction, and Gram stain. Gram-positive, catalase-negative cocci were defined as Streptococcus spp. A single colony of the presumptive Streptococcus spp isolate was streaked over the surface of a $0.1 \%$ esculin, $5 \%$ blood agar plate and grown for a further $24 \mathrm{~h}$. A loopful of this growth was placed in each of 7 sugar reagents, and an isolate was defined as S. uberis, where the isolate did not ferment raffinose, but did ferment inulin, lactose, mannitol, salicin, sorbitol, and trehalose (Quinn et al., 1999). The remaining half plate of growth was collected onto a commercial transport swab (BBL Culture swab, Becton Dickinson, Sparks, MD) and held at $4^{\circ} \mathrm{C}$ for up to $30 \mathrm{~d}$ until transport to the Institute of Veterinary and Biomedical Sciences, Massey University for PFGE.

\section{DNA Extraction}

Genomic DNA for PFGE was prepared from the $S$. uberis strains according to the methods of Smith and Cantor (1997) and McEllistrem et al. (2000), with some modifications. Briefly, S. uberis isolates were grown on 5\% sheep blood agar (Difco, Becton Dickinson) overnight at $37^{\circ} \mathrm{C}$. The cells were harvested into $3 \mathrm{~mL}$ brain heart infusion broth (Difco) and the optical density of the broth was measured and adjusted to 1.4 at $610 \mathrm{~nm}$. A $75-\mu \mathrm{L}$ aliquot of cells was pelleted by centrifugation at $13,000 \mathrm{rpm}$ for $5 \mathrm{~min}$. Cells were washed once with $150 \mu \mathrm{L}$ of Pett IV buffer $(1 M \mathrm{NaCl}$, $10 \mathrm{~m} M$ Tris-HCl [pH 8.0], $10 \mathrm{~m} M$ EDTA; $\mathrm{pH}$ 8.0) then centrifuged and resuspended in $50 \mu \mathrm{L}$ Pett IV buffer. The bacterial suspension was mixed with $100 \mu \mathrm{L}$ of $1 \%$ low melt preparative grade agarose (Bio-Rad Laboratories (New Zealand) Pty Ltd, Auckland, New Zealand) and was dispensed into plug molds. After being solidified for $1 \mathrm{~h}$ on ice, the plugs were incubated overnight at $37^{\circ} \mathrm{C}$ in a lysis buffer solution $(1 M \mathrm{NaCl}$, $100 \mathrm{~m} M$ EDTA [pH 8.0] $6 \mathrm{~m} M$ Tris-HCl [pH 8.0], 0.5\% Brij 58, 0.5\% sodium deoxycholate, $0.5 \%$ sodium lauroyl sarcosine) containing $20 \mathrm{mg}$ of lysozyme/mL (Roche Diagnostics, Auckland, New Zealand). The plugs were transferred into $1 \mathrm{~mL}$ ESP buffer $(0.5 M$ EDTA, $1 \%$ sodium lauroyl sarcosine) containing $1 \mathrm{mg}$ proteinase $\mathrm{K} / \mathrm{mL}$ and were incubated overnight at $56^{\circ} \mathrm{C}$. Following lysis, the plugs were washed 5 times for $1 \mathrm{~h}$ each time with $10 \mathrm{~mL}$ of TE buffer $(10 \mathrm{mM}$ Tris-HCl, $1 \mathrm{~m} M$ EDTA) on ice.

\section{Restriction Endonuclease Digestion}

A 3-mm slice of each plug was equilibrated in 100 $\mu \mathrm{L}$ of $1.2 \times$ restriction buffer (New England Biolabs, Beverly, MA) for 45 min on ice. The restriction buffer was removed and replaced with $100 \mu \mathrm{L}$ of fresh one 
Table 2. Duration of infection (d) of 69 glands with Streptococcus uberis initially diagnosed with infection around calving and sampled at approximately 28-d intervals. The duration is estimated as 1) from initial isolation to half way between the final isolation and first non-isolation, except where a gland was diagnosed with clinical mastitis in which case the duration was taken as the interval from initial isolation to day of clinical diagnosis; 2) from initial isolation to half way between the final isolation and first non-isolation but also including the time following a diagnosis of clinical mastitis; 3 ) as for 1 except that a change in pulsedfield gel electrophoresis (PFGE) type was defined as the end of an infection; and 4) as for 2 except that a change in PFGE type was interpreted as the end of infection.

\begin{tabular}{lcccc}
\hline & $\begin{array}{l}\text { Duration excluding } \\
\text { clinical period }\end{array}$ & $\begin{array}{l}\text { Duration including } \\
\text { clinical period }\end{array}$ & $\begin{array}{l}\text { Duration of unique } \\
\text { PFGE type }\end{array}$ & $\begin{array}{l}\text { Durating } \\
\text { clinical period with } \\
\text { unique PFGE type }\end{array}$ \\
\hline Mean & 31.1 & 32.2 & 24.5 & 24.5 \\
SD & 48.5 & 48.0 & 44.6 & 44.6 \\
Minimum & 0 & 0 & 0 & 0 \\
Maximum & 278 & 278 & 278 & 278 \\
Percentile & & & & 10.75 \\
25th & 10.75 & 12 & 16.75 & 16 \\
50th & 16 & 21.5 & 19 & 24.4 \\
75th & 21.5 & 15.4 & 24.4 & 0.6 \\
Kurtosis & 15.0 & 0.6 & 0.6 & 4.8 \\
SE kurtosis & 0.6 & 3.7 & 4.8 & 0.3 \\
Skewness & 3.6 & 0.3 & 0.3 & \\
SE skewness & 0.3 & & & \\
\hline
\end{tabular}

$\times$ restriction buffer containing 30 units of $S m a \mathrm{I}$ (New England Biolabs). The plug slices were held on ice for an additional 45 min before an overnight incubation at $25^{\circ} \mathrm{C}$.

\section{PFGE}

The restriction fragments were separated by PFGE on a CHEF-DRII system in a 1\% agarose gel (Pulsed Field Certified Agarose, Bio-Rad Laboratories (New Zealand) Pty Ltd.) in $0.5 \times$ TBE buffer ( $45 \mathrm{~m} M$ Tris, $45 \mathrm{~m} M$ Boric acid, $1 \mathrm{~m} M$ EDTA; $\mathrm{pH} 8.0$ ) at $14^{\circ} \mathrm{C}$. The gel was run at $6 \mathrm{~V} / \mathrm{cm}$ for $23 \mathrm{~h}$ with an initial pulse time of $1 \mathrm{~s}$ and a final pulse time of $40 \mathrm{~s}$. Lambda Ladder PFG Marker and Low Range PFG Marker (New England Biolabs) were included as molecular size standards. Twenty unknown samples were run on each gel in date order without regard to farm of origin or cow. Thus, repeated S. uberis isolations from the same cow might have been run and, hence, analyzed on different gels.

\section{Analysis of PFGE Patterns}

Gels were stained with ethidium bromide, and images were captured under ultraviolet illumination by the Gel Doc 2000 (Bio-Rad Laboratories (New Zealand) Pty Ltd.). The PFGE patterns were analyzed by Diversity Database software (Bio-Rad Laboratories (New Zealand) Pty Ltd). Similarities between the PFGE patterns were calculated by the Dice correlation coefficient with a maximum position tolerance of $1 \%$. Dendrograms were constructed by the un- weighted pair group method with arithmetic mean (UPGMA). Where the level of similarity between isolates was $>60 \%$ on the dendrograms, the PFGE patterns were compared visually. Multiple isolates from the same cow were also visually assessed. Where the level of similarity was unclear, isolates were rerun on the same gel. Minor differences i.e., $<3$ band differences were recorded as subtypes, but treated as one PFGE type for analysis.

\section{Statistical Analysis}

The duration of infection of glands diagnosed with subclinical $S$. uberis infections were not normally distributed (Table 2) with most intervals being $<20 \mathrm{~d}$, but with a few longer intervals. Thus, data are presented as the median and percentiles (Table 2). The duration was further examined using Kaplan-Meier or Cox's proportion hazards models ("survival analysis"). Analysis was performed for each of the 4 definitions described previously. Initially, factors thought to affect the duration of infection (including age [coded as $2 \mathrm{yr}$ old or $>2 \mathrm{yr}$ old], herd of origin, days postpartum at enrollment, whether the gland was a front or rear gland, number of glands infected within a cow, and the SCC [and $\log _{10}$ SCC] of the gland at the time of enrollment) were tested in univariate models. Factors associated (i.e., $P<0.2$ ) were then offered to a reverse stepwise model using likelihood ratios as the factor exclusion method. Glands were defined as right-censored when infection persisted to the end of lactation. The validity of the models was assessed by examination of the hazards ratio and log minus log plots. 


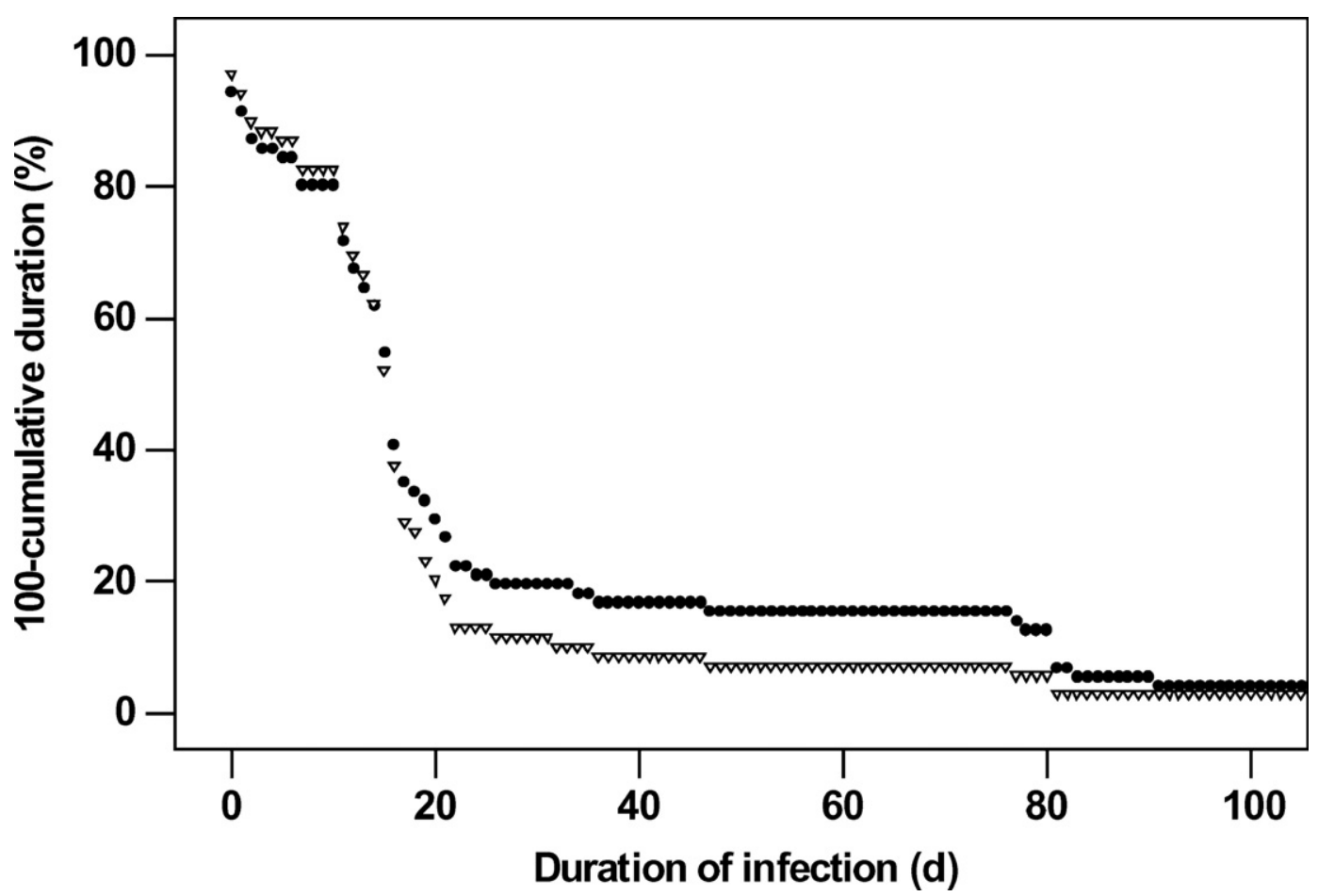

Figure 1. Survival (i.e., probability of being infected) of any Streptococcus uberis (conventional; $\nabla$ ) infection and of PFGE-specific Streptococcus uberis pulsed-field gel electrophoresis type $(-)$ of individual glands infected with Streptococcus uberis.

The proportion of glands diagnosed with clinical mastitis that were subsequently bacteriologically negative (i.e., the 'cure proportion') was analyzed using logistic regression. The age code (i.e., 2 yr old or $>2$ yr old), breed, and days postpartum (coded as 0 to 1 , 2 to 3,4 to 25 , and $>25$ d postpartum at the time of diagnosis, which represent approximately quartiles of

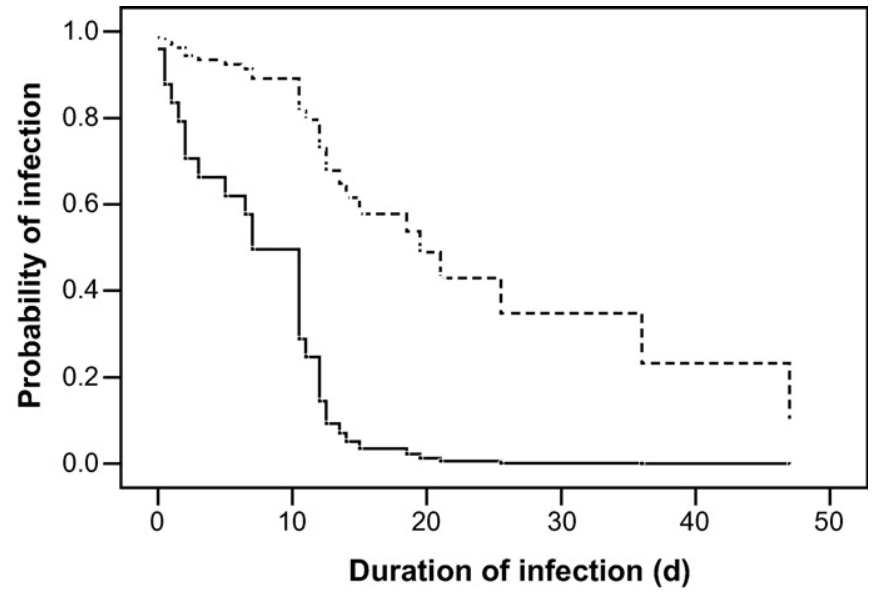

Figure 2. Survival (i.e., probability of being infected) of individual glands infected with Streptococcus uberis in heifers (solid line) or cows (dashed line). the number of cases by days postpartum) were initially tested by univariate methods (i.e., $\chi^{2}$ ). If these factors were associated with bacteriological cure proportion $(P<0.2)$, they were then offered to a reverse stepwise logistic regression model. The effect of age code (i.e., 2, 3, 4 to 8 , and $>8$ yr old), herd of origin, and days postpartum at diagnosis (coded into quartiles as

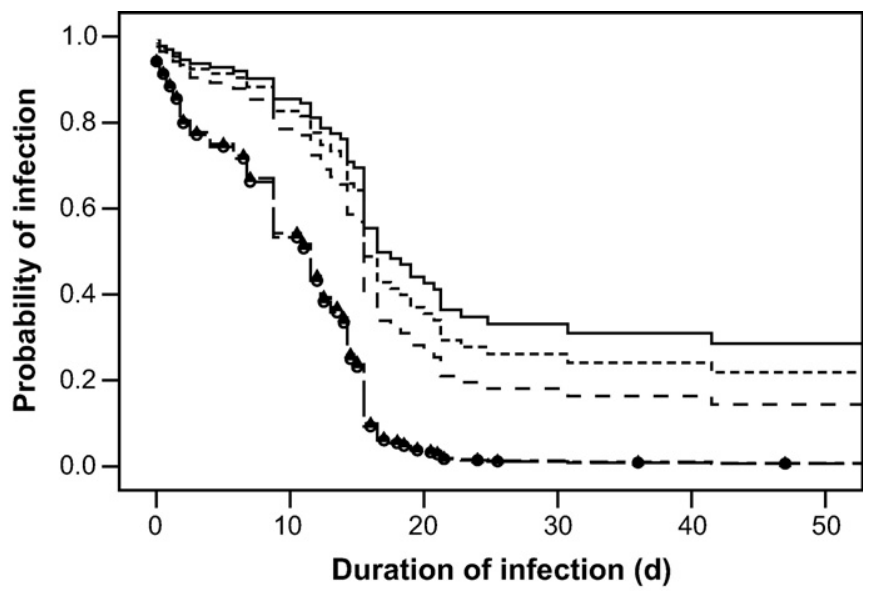

Figure 3. Survival (i.e., probability of being infected) of individual glands infected with Streptococcus uberis in 5 herds with each herd represented by a separate line type. 
Table 3. Bacteria isolated from glands diagnosed with clinical mastitis by herd owners.

\begin{tabular}{|c|c|c|c|}
\hline Isolate & $\mathrm{n}$ & All samples & $\begin{array}{l}\text { Bacteria-positive } \\
\text { isolates }\end{array}$ \\
\hline & & & \\
\hline No growth & 40 & 29.0 & \\
\hline Staphylococcus aureus & 3 & 2.2 & 3.4 \\
\hline $\begin{array}{l}\text { Coagulase-negative } \\
\text { staphylococci }\end{array}$ & 10 & 7.2 & 11.5 \\
\hline Streptococcus uberis & 55 & 39.9 & 63.2 \\
\hline Streptococcus agalactiae & 3 & 2.2 & 3.4 \\
\hline Other streptococci & 2 & 1.4 & 2.3 \\
\hline Escherichia coli & 4 & 2.9 & 4.6 \\
\hline Others & 10 & 7.2 & 11.5 \\
\hline Contaminated $^{1}$ & 11 & 8.0 & \\
\hline Total & 138 & 100.0 & 100.0 \\
\hline
\end{tabular}

${ }^{1}>3$ distinct colony types present.

above) on the proportion of clinical cases from which S. uberis was isolated was analyzed by $\chi^{2}$.

The trial was performed following approval by the Animal Ethics Committee of AgResearch, Ruakura and the Massey University Animal Ethics Committee.

\section{RESULTS}

\section{Bacteriology}

Forty percent of cows and $19 \%$ of glands had intramammary infections when sampled within 1 to $3 \mathrm{~d}$ of calving (Table 1). Streptococcus uberis was isolated from $12 \%$ of all cows and $4 \%$ of all glands (Table 1 ). A total of 59 cows and 71 glands were enrolled with subclinical $S$. uberis infection after this initial sampling. Forty-two cows had one S. uberis-infected gland, 13 had 2 S. uberis-infected glands, and one cow had $3 S$. uberis-infected glands at enrolment.

\section{Duration of Subclinical S. uberis Infection}

The majority of $S$. uberis-infected glands underwent spontaneous bacteriological cure (55 of 71 [78\%]), with a small number lost to follow up (2 of 71 [3\%]), diagnosed with clinical mastitis (9 of 71 [13\%]) or were still infected at the end of lactation (5 of $71[7 \%]$ ).

The median duration of infection was $16 \mathrm{~d}$ for all 4 definitions of duration (50th percentile; Table 2; Fig-

Table 4. Proportion of clinical mastitis cases bacteriologically cured (all pathogens) by DIM at diagnosis.

\begin{tabular}{lllr}
\hline & & \multicolumn{2}{c}{ Cured } \\
\cline { 3 - 4 } DIM at diagnosis & Total cows & (no.) & $(\%)$ \\
\hline 0 to $1 \mathrm{~d}$ & 21 & 21 & 100.0 \\
2 to $3 \mathrm{~d}$ & 22 & 21 & 95.5 \\
4 to $25 \mathrm{~d}$ & 15 & 13 & 86.7 \\
$>25 \mathrm{~d}$ & 19 & 14 & 73.7 \\
Total & 77 & 69 & 89.6 \\
\hline
\end{tabular}

ure 1), but with numerically shorter 25 th and 75 th percentiles for the estimates that took account of changes in PFGE type (Table 2). Inclusion of the period of infection following diagnosis of clinical mastitis did not increase the estimated median duration of infection (Table 2). The duration of infection (Definition 1) was longer for cows than heifers (12 [95\% CI = 7 to 17 ] vs. 11 [95\% CI $=5$ to 15] median $d$ for cows and heifers, respectively; $P=0.001$; Figure 2, hazards ratio $=6.0[95 \% \mathrm{CI}=2.1$ to 17.4$]$ ) and varied among herds $(P=0.01$; Figure 3$)$. Duration of infection was unaffected by whether a cow had only one or more than one gland infected with $S$. uberis $(P=0.79)$, the day postpartum at enrolment postpartum $(P=0.32)$, whether the gland was a front or rear gland $(P=0.79)$ or by the SCC or $\log _{10}$ SCC of the gland at enrolment ( $P=0.81$ and $P=0.47$, respectively). The same variables were significant with similar hazards ratios when the other 3 methods of calculating duration were tested as the dependent variables (data not presented).

\section{Clinical Mastitis}

A total of 101 cows and 138 glands were diagnosed with clinical mastitis. Mastitis was diagnosed in one, 2,3 , and 4 glands in $79.6,14.2,1.8$, and $4.4 \%$ of cows, respectively.

Streptococcus uberis was the most prevalent pathogen isolated from cases of clinical mastitis (63.2\%; Table 3) with 'others' and coagulase-negative staphylococci the next most common isolates. The proportion of glands from which $S$. uberis was isolated did not differ among herds $(P=0.57)$, age codes (18 of 42 (43\%), 2 of $8(25 \%), 37$ of $88(42 \%)$, and 8 of $25(32 \%)$ for $2,3,4$ to 8 , and $>8$ yr old cows, respectively; $P=$ 0.64 ), or vary with time postpartum (20 of 43 [47\%], 18 of 40 [45\%], 13 of 30 [43\%], and 13 of 48 [27\%] for 0 to 1,2 to 3,4 to 25 , and $>25$ d postpartum at diagnosis, respectively; $P=0.18$ ). The proportion of glands that underwent bacteriological cure was $89.6 \%$, and this proportion declined with increasing days postpartum at diagnosis (Table $4 ; P=0.03$ ).

\section{PFGE Analyses}

A total of 173 different PFGE types were identified from a total of $234 \mathrm{~S}$. uberis isolates (Table 5). An example of a PFGE gel is presented in Figure 4, and the dendrogram constructed from isolates from one herd (Herd A) is presented in Figure 5.

Each farm had a unique set of PFGE types; that is, in no case was the same PFGE type isolated from more than one herd. In 4 of the 5 herds, each PFGE type 
Table 5. Number and percentage of subclinical Streptococcus uberis pulsed-field gel electrophoresis (PFGE) types.

\begin{tabular}{|c|c|c|c|c|c|c|}
\hline & \multicolumn{5}{|c|}{ Herd } & \multirow[b]{2}{*}{ Tota } \\
\hline & A & B & $\mathrm{C}$ & $\mathrm{D}$ & $\mathrm{E}$ & \\
\hline Strep. uberis isolates tested, $\mathrm{n}$ & 32 & 67 & 52 & 19 & 64 & 234 \\
\hline PFGE types, $\mathrm{n}$ & 18 & 54 & 34 & 17 & 50 & 173 \\
\hline $\begin{array}{l}\text { Glands with multiple } S \text {. uberis isolates across time, }{ }^{1} \text { no. } \\
\text { Glands with same PFGE type across time }{ }^{2}\end{array}$ & 4 & 6 & 4 & 3 & 12 & 29 \\
\hline no. & 4 & 5 & 4 & 1 & 2 & 16 \\
\hline$\%$ & 100 & 83.3 & 100 & 33.3 & 16.7 & 55.2 \\
\hline \multicolumn{7}{|l|}{ Number of PFGE types in multiple cows ${ }^{3}$} \\
\hline $\mathrm{n}$ & 0 & 0 & 0 & 0 & 3 & 3 \\
\hline$\%^{4}$ & 0 & 0 & 0 & 0 & 10.3 & 5.1 \\
\hline $\begin{array}{l}\text { Cows with multiple glands infected with } S \text {. uberis, no. } \\
\text { Cows with the same PFGE type in multiple glands }{ }^{5}\end{array}$ & 2 & 11 & 6 & 4 & 12 & 35 \\
\hline no. & 1 & 1 & 1 & 0 & 2 & 5 \\
\hline$\%$ & 50 & 9.1 & 16.7 & 0 & 16.7 & 14.3 \\
\hline $\begin{array}{l}\text { Cows with multiple } S \text {. uberis isolates across time }{ }^{6} \text { no. } \\
\text { Cows with same PFGE type across time }{ }^{7}\end{array}$ & 1 & 6 & 3 & 2 & 6 & 18 \\
\hline $\begin{array}{l}\text { no. } \\
\%\end{array}$ & $\begin{array}{r}1 \\
100\end{array}$ & $\begin{array}{c}4 \\
66.7\end{array}$ & $\begin{array}{c}2 \\
66.7\end{array}$ & $\begin{array}{c}1 \\
50.0\end{array}$ & $\begin{array}{c}1 \\
16.7\end{array}$ & $\begin{array}{c}9 \\
50.0\end{array}$ \\
\hline
\end{tabular}

${ }^{1}$ Glands from which Strep. uberis was isolated on more than one occasion over time.

${ }^{2}$ Glands from which the Strep. uberis PFGE type was isolated on more than one occasion over time.

${ }^{3}$ Number of cows within a herd from which the same Strep. uberis PFGE type was isolated.

${ }^{4}$ The denominator is the total number of cows from which Strep. uberis was isolated.

${ }^{5}$ At least 2 glands with the same PFGE type within the same cow (either simultaneously or over time).

${ }^{6}$ Cows from which Strep. uberis was isolated from one or more glands on more than one occasion over time.

${ }^{7}$ Cows from which the same Strep. uberis PFGE type was isolated from one or more glands on more than one occasion over time.

was unique to one cow. In Herd E, 3 PFGE types were recovered from 2 cows each (Table 5).

For glands from which $S$. uberis was isolated on more than one occasion, 55\% (16 of 29) had the same PFGE type (Table 5). However, there was a range among herds, with between 16\% (Herd E) and 100\% (Herds A and C) of glands having the same PFGE type on more than one occasion in the same gland (Table 5).

Only $14 \%$ of cows that had multiple glands infected with $S$. uberis simultaneously had the same PFGE type in $\geq 2$ glands (Table 5 ).

Half of the cows (9 of 18) from which more than one $S$. uberis isolate was recovered over time had the same PFGE type within cow over time (Table 5).

Isolates from 2 glands had isolates showing minor variations in the PFGE banding pattern over time. For example, the PFGE pattern of isolates from one gland over a 4-mo period showed 3 closely related PFGE types (designated L2, L2a, and L2b; Figure 6).

\section{PFGE Types of S. uberis Associated with Apparent Clinical Treatment Failures}

Isolates of $S$. uberis recovered from 4 glands posttreatment of clinical mastitis were examined. The antibiotic sensitivity of each of the isolates was tested using the Kirby-Bauer disc diffusion method, and all isolates were sensitive to penicillin. In 2 of the 4 cases, the PFGE type changed following treatment (Table 6). However, these changes were relatively minor as the PFGE types had 75 and $92 \%$ similarity with the original isolates (Table 6). In one case, the same PFGE type as that recovered pre-treatment was re-isolated following 2 samplings (at 28-d intervals) where no bacteria were isolated.

\section{DISCUSSION}

The median duration of $S$. uberis subclinical infection was $16 \mathrm{~d}$ in the present trial. This is shorter than the duration of 28 to $46 \mathrm{~d}$ reported from a Dutch study (Zadoks et al., 2001), a report that $62 \%$ of S. uberis cases have a duration of $<31 \mathrm{~d}$ (Todhunter et al., 1995) and estimates of $95 \mathrm{~d}$ and 2.8 to 9 mo from other studies (Lam, 1996; Watt, 1999). The duration of infection in the current study might have been underestimated as some cows could have been infected for a significant period of time before the experiment commenced (i.e., left-censored) and some remained infected at the end of sampling (i.e., right-censored). This underestimation may be substantial, as approximately $32 \%$ of new S. uberis infections are reported to 


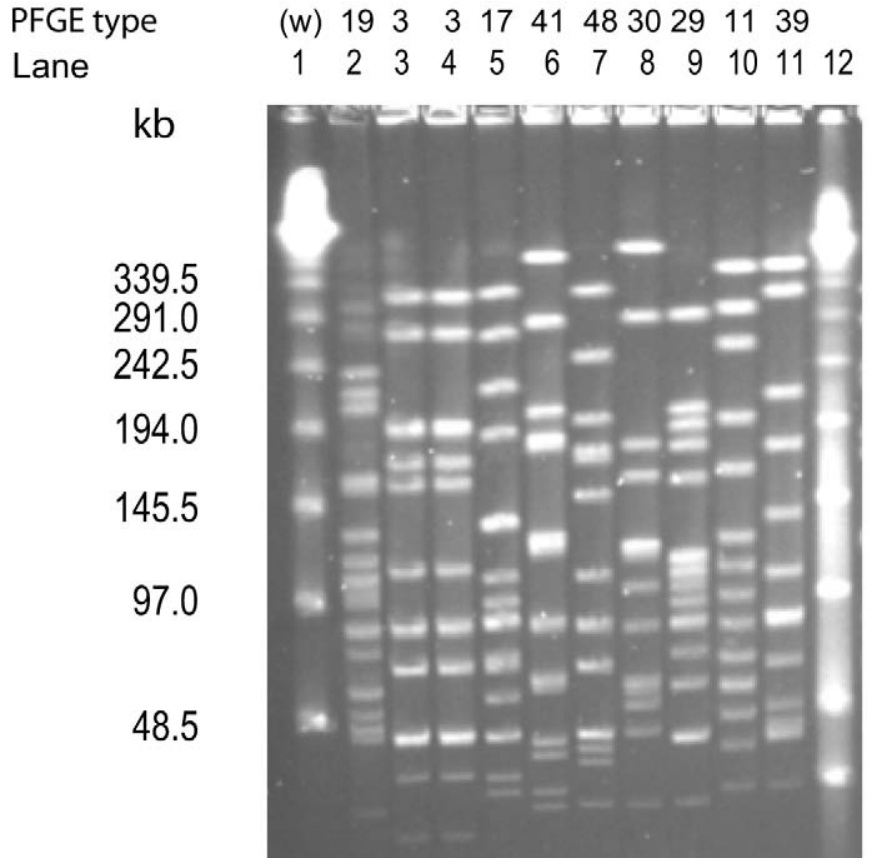

Figure 4. Example of pulsed-field gel electrophoresis (PFGE) of SmaI macrorestriction fragments of Streptococcus uberis isolates of bovine origin. The top line above the gel indicates the PFGE type assigned to that isolate; the second line indicates the lane numbers with lane 1 = low range PFG marker and lane $12=$ the Lambda Ladder PFG Marker (New England Biolabs).

occur in the dry period and $36 \%$ of S. uberis infections present at calving are acquired in the first half of the dry period (Todhunter et al., 1995). Other studies estimating duration might also have left censoring of some animals. The current study enrolled $S$. uberis infected cows around calving while other studies have enrolled cows throughout lactation (Zadoks et al., 2001, 2003). As the duration of infection has been shown to be shorter for infections detected at calving than later in lactation (e.g., 9 vs. $46 \mathrm{~d}$ for infections detected at calving compared with other times; Zadoks et al., 2003), the current estimate may be shorter than the average for infections across an entire lactation. A novel finding of this study was that cows (i.e., $>2$ yr old) had a longer duration of infection than heifers (i.e., 2 yr olds). A previous study did not find any effect of age on duration of $S$. uberis infection (Watt, 1999). The reason for the longer duration in older cows is not clear. The reason for the reported differences among herds in duration of infection is not known but may include factors related to milking management, nutrition, and/or cow genetics. It was assumed for the analysis of duration of infection that isolation of $S$. uberis at each sampling at 28-d intervals constituted continuous infection between samples. However, it is possi- ble that spontaneous cure and re-infection with the same PFGE type could have occurred within the 28$\mathrm{d}$ period, but with the high degree of heterology of $S$. uberis isolates within herds, this appears an unlikely possibility. A higher frequency of sampling and use of PFGE typing may help elucidate the extent that this occurs. In the initial analysis, changes in the PFGE type were ignored. However, as $45 \%$ of glands had changes in PFGE type over time, the duration was re-analyzed, taking account of the changes, and it was assumed that a change in PFGE type represented a new infection and that the initial infection had ended at the time of the change. The median duration of infection was unchanged when PFGE type and period of infection following clinical was taken into account. This was likely because only a small number of glands ( $\mathrm{n}=9 ; 13 \%)$ were diagnosed with clinical mastitis, and in each case the gland underwent bacteriological cure following treatment.

Multiple S. uberis PFGE types were identified both within and between farms in the present study. Previous studies have also identified a large number of $S$. uberis strains on farms in New Zealand (Douglas et al., 2000; Wieliczko et al., 2002) and elsewhere (Hill and Leigh, 1989; Jayarao et al., 1992; Phuektes et al., 2001; Zadoks, 2002). In the present study, the same PFGE type was only found in 2 different cows on 3 occasions, and all of these cows were in the same herd. Approximately only one-half of the cows and one-half of the glands with chronic infections had the same PFGE type over time. Additionally, in only $14 \%$ of cows in which multiple glands were infected did the same PFGE type occur in the same animal. These data suggest that in most cases infection occurs from a source other than an infected cow. In contrast to the current study, a predominant $S$. uberis type has been identified within some herds in other studies. For example, $50 \%$ (5 of 10) and 78\% (22 of 28) of cows from which $S$. uberis were isolated had the same strain type within 2 herds in a Dutch study, respectively (Zadoks et al., 2003). The same strain type was found in $88 \%$ of infections from which multiple samples were collected (Zadoks, 2002). The same strain type was identified in each gland where a cow had multiple glands infected simultaneously (Zadoks et al., 2003). A predominant strain was also identified in 2 of 4 herds in an Australian study (Phuektes et al., 2001). It was concluded from these 2 studies that significant cow-to-cow transmission was occurring. The greater degree of heterogeneity of $S$. uberis types in the present study and a failure to find a dominant type may reflect differences in the epidemiology of $S$. uberis infection among production systems. Under the extensive pasture systems in New Zealand, it appears that 


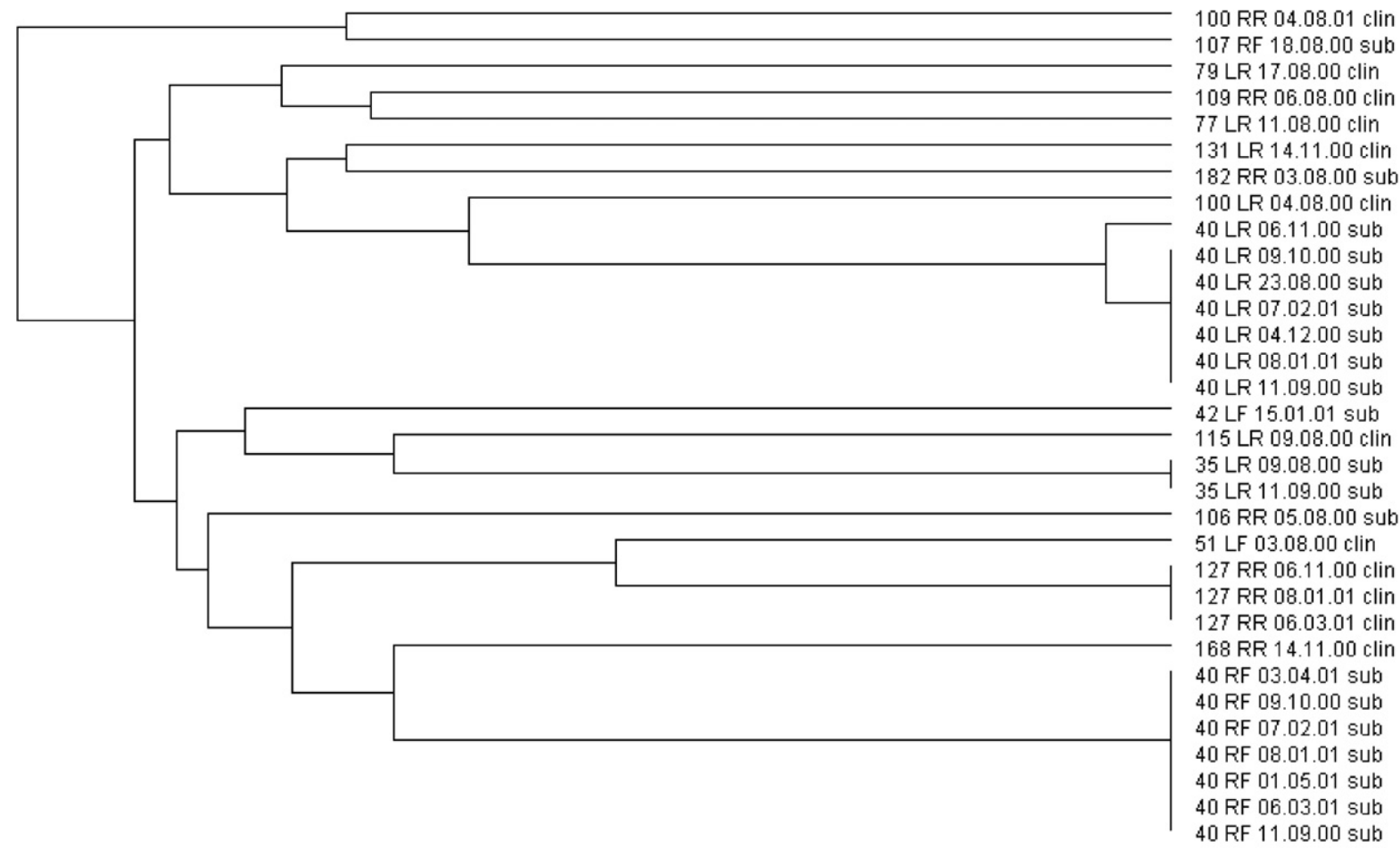

Figure 5. Dendrogram of Streptococcus uberis isolates from Herd A. The coding on the right-hand side of the diagram indicates the cow number ( 2 or 3 digits), the gland (i.e., $\mathrm{LF}=$ left front, $\mathrm{LR}=$ left rear, $\mathrm{RF}=$ right front, and $\mathrm{RR}=$ right rear), the calendar date of isolation (dd.mm.yy), and the clinical status of the gland (i.e., clinical [clin] or subclinical [sub]). The level of relatedness is indicated by the horizontal scale at the top of the diagram with $1=$ indistinguishable, $0=$ unrelated.

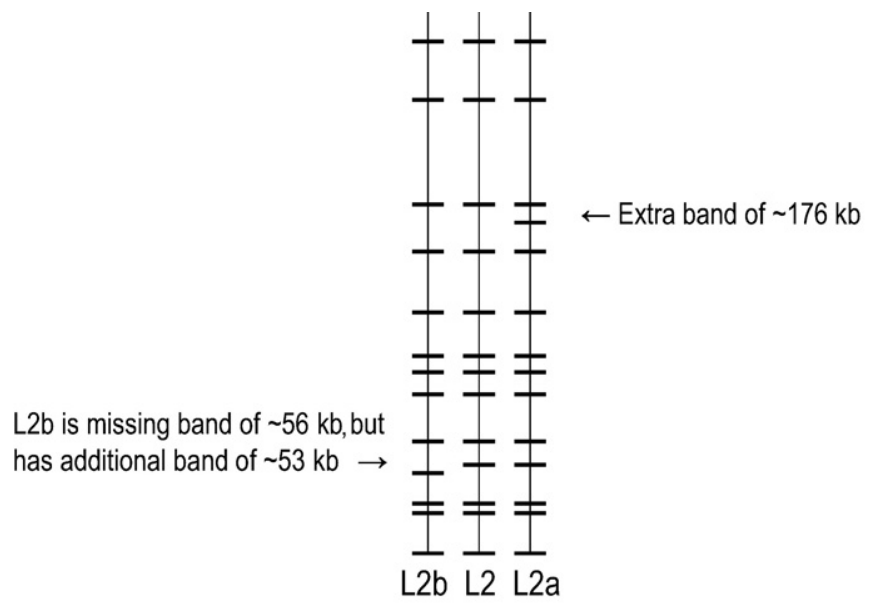

Figure 6. Diagrammatic representation of pulsed-field gel electrophoresis patterns of Streptococcus uberis isolates L2, L2a, and L2b all from cow 235, left rear gland, Herd C, isolated between January and May 2001. a point source of $S$. uberis infection is uncommon and that transmission of $S$. uberis may be predominantly from environmental sources.

Where isolates differ by only 2 to 3 PFGE bands, it has been suggested that this may represent a single point change in the genome and that the types are closely related (Tenover et al., 1995). Two isolates differed by only 1 or 2 bands when isolated sequentially from the same glands over time in the present study. In one of these cases, the change occurred following treatment of clinical mastitis with an antibiotic that did not result in bacterial cure of the gland. It is plausible that treatment resulted in a genotype change that allowed the isolate to survive antibiotic treatment. However, no change in antibiotic sensitivity was demonstrated following testing using the Kirby Bauer disc diffusion method for these 2 PFGE types.

In the small number of glands treated for clinical mastitis and in which subsequent sampling suggested that treatment failure had occurred, different PFGE types were isolated post-treatment compared with 
Table 6. Pulsed-field gel electrophoresis (PFGE) types of clinical Streptococcus uberis isolates before (pretreatment) and after (Post 1 to Post 5) treatment where there was apparent failure of bacteriological cure.

\begin{tabular}{|c|c|c|c|c|c|c|c|c|c|c|}
\hline \multirow[b]{2}{*}{ Herd } & \multirow[b]{2}{*}{ Cow } & \multirow[b]{2}{*}{ Gland $^{1}$} & \multirow{2}{*}{$\begin{array}{l}\text { Date of } \\
\text { treatment }\end{array}$} & \multicolumn{6}{|c|}{ PFGE type } & \multirow[b]{2}{*}{$\operatorname{Rel}^{2}$} \\
\hline & & & & Pre-treatment & Post 1 & Post 2 & Post 3 & Post 4 & Post 5 & \\
\hline B & 133 & $\mathrm{RR}$ & Jan 2 & K6 & K6 & no growth & no growth & K6 & & 1.00 \\
\hline B & 133 & LR & Jan 2 & K1 & $\mathrm{K} 1$ & $\mathrm{~K} 1$ & $\mathrm{~K} 1$ & K1 & & 1.00 \\
\hline $\mathrm{C}$ & 65 & LR & Dec 14 & L6 & $\mathrm{L} 4$ & $\mathrm{~L} 4$ & L4 & & & 0.75 \\
\hline $\mathrm{C}$ & 235 & $\mathrm{RF}$ & Jan 9 & L2a & L2 & L2 & L2 & L2 & $\mathrm{L} 2 \mathrm{~b}$ & 0.92 \\
\hline
\end{tabular}

${ }^{1} \mathrm{RR}=$ Right rear, $\mathrm{LR}=$ left rear, and $\mathrm{RF}=$ right front.

${ }^{2}$ Degree of similarity between $S$. uberis PFGE types before and after treatment: $1=$ indistinguishable and $0=$ no relationship.

pre-treatment. However, it is not clear if bacteriological cure had indeed occurred and a new infection had subsequently become established, whether treatment itself resulted in a change in the PFGE type profile, or whether, in fact, multiple PFGE types were present pre-treatment but only one identified because of the laboratory techniques used (see subsequent).

In the present study, clinical mastitis was not associated with any particular strain type. In contrast, in a previous Australian study, one PFGE type was more commonly associated with clinical mastitis than other PFGE types (Phuektes et al., 2001). Those researchers suggested that the predominant stain had a virulence factor(s) not present in other strains endemic in the herd. In contrast, another study failed to find that different PFGE types had a different probability of being associated with clinical mastitis (Zadoks et al., 2001). Variations in virulence have been previously demonstrated among $S$. uberis strains (Hill, 1988). No one PFGE type or group of PFGE types were more likely to be associated with prolonged subclinical infection, diagnosis with clinical mastitis, or a failure to cure following treatment in the current study. Thus, cows in this population are likely to have been exposed to a range of $S$. uberis PFGE types, and the duration of infection and clinical outcome (i.e., diagnosed as clinical or not) may be related to cow factors or dose of $S$. uberis rather than to the specific PFGE type the gland was infected with.

A limitation of the present study, and many other studies, is that only one colony type from a number of colonies grown during initial culture was genotyped, because of the expense of PFGE. However, given the large number of $S$. uberis PFGE types identified, it is possible that multiple PFGE types might have been present concurrently within a single gland. Two PFGE types of $S$. uberis in the same gland at the same time have been previously reported as they were phenotypically different and readily distinguishable on the primary culture plate (Zadoks, 2002). Further studies are required to determine the prevalence of multiple
S. uberis PFGE type infections within the same gland. This is important as where only one colony type is tested and where multiple PFGE types are concurrently present, it may be falsely assumed that new infections are occurring over time as the PFGE type appears to change with time, when in fact it is just chance that one or other of the infecting strains is actually selected for typing at sequential sampling times.

It was concluded that there are many different PFGE types of $S$. uberis present within the New Zealand environment, that cow-to-cow transmission of $S$. uberis is likely uncommon relative to transmission from environmental sources, that changes in PFGE type within chronically infected glands are relatively common, that PFGE type is not correlated with the diagnosis of clinical mastitis, and that the duration of infection may be overestimated where the PFGE type of the infection is not known.

\section{ACKNOWLEDGMENTS}

The patience of the herd owners in allowing repeated sampling of cows within their herds and for collecting milk samples from clinical mastitis cases is gratefully acknowledged. The financial support of Schering Plough Animal Health (Upper Hutt, New Zealand) is also gratefully acknowledged.

\section{REFERENCES}

Baseggio, N., P. D. Mansell, J. W. Browning, and G. F. Browning. 1997. Strain differentiation of isolates of streptococci from bovine mastitis by pulsed-field gel electrophoresis. Mol. Cell. Prob. $11: 349-354$.

Bramley, A. J., and F. H. Dodd. 1984. Reviews of the progress of dairy science: mastitis control-Progress and prospects. J. Dairy Res. 51:481-512.

Cullen, G. A. 1966. The ecology of Streptococcus uberis. Br. Vet. J. 122:333-339.

Douglas, V. L., S. G. Fenwick, D. U. Pfeiffer, N. B. Williamson, and C. W. Holmes. 2000. Genomic typing of Streptococcus uberis isolates from cases of mastitis in New Zealand dairy cows, using pulsed-field gel electrophoresis. Vet. Microbiol. 75:27-41. 
Gillespie, B. E., B. M. Jayarao, and S. P. Oliver. 1997. Identification of Streptococcus uberis species by randomly amplified polymorphic deoxyribonucleic acid fingerprinting. J. Dairy Sci. 80:471-476.

Gillespie, B. E., B. M. Jayarao, J. W. Pankey, and S. P. Oliver. 1998. Subtyping of Streptococcus dysgalactiae and Streptococcus uberis isolated from bovine mammary secretions by DNA fingerprinting. Zentr. Vet. Reihe B. 45:585-593.

Hill, A. W. 1988. Pathogenicity of two strains of Streptococcus uberis infused into the lactating and non-lactating mammary gland. Res. Vet. Sci. 45:400-404.

Hill, A. W., and J. A. Leigh. 1989. DNA fingerprinting of Streptococcus uberis: a useful tool for epidemiology of bovine mastitis. Epidemiol. Infect. 103:165-171.

Jayarao, B. M., B. J. Bassam, G. Caetano-Anolles, P. M. Gresshoff, and S. P. Oliver. 1992. Subtyping of Streptococcus uberis by DNA amplification fingerprinting. J. Clin. Microbiol. 30:1347-1350.

Lam, T. J. G. M. 1996. Dynamics of bovine mastitis. Ph.D. Diss., Utrecht Univ., The Netherlands.

McDougall, S. 1998. Efficacy of two antibiotic treatments in curing clinical and subclinical mastitis in lactating dairy cows. N.Z. Vet. J. 46:226-232.

McEllistrem, M., J. E. Stout, and L. H. Harrison. 2000. Simplified protocol for pulsed-field gel electrophoresis analysis of Streptococcus pneumoniae. J. Clin. Microbiol. 38:351-353.

Pankey, J. W., P. B. Pankey, R. M. Barker, J. H. Williamson, and M. W. Woolford. 1996. The prevalence of mastitis in primiparous heifers in eleven Waikato dairy herds. N.Z. Vet. J. 44:41-44.

Phuektes, P., P. D. Mansell, R. S. Dyson, N. D. Hooper, J. S. Dick, and G. F. Browning. 2001. Molecular epidemiology of Streptococcus uberis isolates from dairy cows with mastitis. J. Clin. Microbiol. 39:1460-1466.
Quinn, P. J., M. E. Carter, B. K. Markey, and G. R. Carter. 1999. Clinical Veterinary Microbiology. Mosby, Edinburgh, UK.

Smith, C. L., and C. R. Cantor. 1997. Purification, specific fragmentation, and separation of large DNA molecules. Meth. Enzymol. 155:449-467.

Tenover, F. C., R. D. Arbeit, R. V. Goering, P. A. Mikkelson, B. E. Murray, D. H. Persing, and B. Swaminathan. 1995. Interpreting chromosomal DNA restriction patterns produced by pulsed-field gel electrophoresis: criteria for bacterial strain typing. J. Clin. Microbiol. 33:2233-2239.

Todhunter, D. A., K. L. Smith, and J. S. Hogan. 1995. Environmental streptococcal intramammary infections of the bovine mammary-gland. J. Dairy Sci. 78:2366-2374.

Watt, C. J. 1999. The epidemiology of intramammary infection in dairy cows, with particular reference to Streptococcus uberis. Ph.D. Diss., Univ. Oxford, United Kingdom.

Wieliczko, R. J., J. H. Williamson, R. T. Cursons, S. J. Lacy-Hulbert, and M. W. Woolford. 2002. Molecular typing of Streptococcus uberis strains isolated from cases of bovine mastitis. J. Dairy Sci. 85:2149-2154.

Williamson, J. H., M. W. Woolford, and A. M. Day. 1995. The prophylactic effect of a dry-cow antibiotic against Streptococcus-uberis. N.Z. Vet. J. 43:228-234.

Zadoks, R. N. 2002. Molecular and mathematical epidemiology of Staphylococcus aureus and Streptococcus uberis mastitis in dairy herds. Ph.D. Diss., Utrecht Univ., The Netherlands.

Zadoks, R. N., H. G. Allore, H. W. Barkema, O. C. Sampimon, Y. T. Grohn, and Y. H. Schukken. 2001. Analysis of an outbreak of Streptococcus uberis mastitis. J. Dairy Sci. 84:590-599.

Zadoks, R. N., B. E. Gillespie, H. W. Barkema, O. C. Sampimon, S. P. Oliver, and Y. H. Schukken. 2003. Clinical, epidemiological and molecular characteristics of Streptococcus uberis infections in dairy herds. Epidemiol. Infect. 130:335-349. 